\title{
Age estimation by pulp/tooth area ratio in upper canines: Cameriere's method assessed in a Polish population sample using digital panoramic radiography
}

Natalie Namięta ( $\square$ n.lerska@hotmail.com )

Medical University of Lublin https://orcid.org/0000-0001-9821-3909

Ingrid Różyło-Kalinowska

Uniwersytet Medyczny w Lublinie

Paweł Kalinowski

Uniwersytet Medyczny w Lublinie

Magdalena Piskórz

Uniwersytet Medyczny w Lublinie

Research article

Keywords: Age estimation, Dental imaging, Secondary dentine, Pulp-tooth area, Orthopantomogram

Posted Date: April 1st, 2020

DOI: https://doi.org/10.21203/rs.3.rs-19412/v1

License: (c) (1) This work is licensed under a Creative Commons Attribution 4.0 International License.

Read Full License 


\section{Abstract}

Background: Various methods are available to assess the age of a child. However, it is much more difficult to evaluate the age of an adult just on the basis of orthopantomographs (OPGs). Cameriere's method based on measurement of pulp/tooth ratio is one of few methods that allows to determine the age of any human being. The aim of this study is to estimate the validation of this method in a Polish population.

Materials: OPGs taken in the Department of Dental and Maxillofacial Radiology, Medical University of Lublin, Poland were retrospectively selected for the study. The selection criteria involved a good quality OPG with a free from any pathology upper right canine. The sample included 521 individuals (271 females and 250 males) aged from 18 to 70 years. After tracing and estimating the pulp/tooth area ratio (AR) a dental age was calculated. Afterwards, it has been compared with the chronological age of each patient. Regression models were developed for prediction of the chronological age. Statistical analysis was performed using the Statistica for Windows software (StatSoft).

Results: The regression formula for the total group was as follows: age $=91.746-481.6$ AR. The dental age calculated using these formulations highly correlated with the chronological age. Pearson's correlation coefficient equalled -0.844 for the whole group, $r=-0.873$ in females and $r=-0.815$ in males. All correlations were statistically significant $(p=0.00)$.

Conclusions: Cameriere's method can be used in evaluating the dental age in the adult Polish population.

\section{Background}

Throughout the years various approaches have been proposed to estimate the age of an individual, including evaluation of radiographs. However, finding an accurate and consistent method has always been a challenge, especially in racially diverse populations (1). Initially the methods for evaluating age in children were developed, mainly as an integral part of both diagnosis and treatment of pediatric patients. The elaborated radiographic methods based on skeletal radiographs, but X-rays applied in dentistry can be valuable, too. For example, lateral cephalometric radiographs allow observation of changes of shape of cervical vertebra during development, and the method is called the Cervical Vertebrae Maturation (CVM) system (2,3). In children dental age (DA) estimation can be performed using several methods, including those by Nolla, Demirjian and Cameriere $(2,4)$. Once the age of majority is approaching, the only teeth available for dental age estimation are third molars. The third molar maturity index $\left(\mathrm{I}_{3} \mathrm{M}\right)$ was proposed by Cameriere to discriminate between adolescents and young adults, and the method has recently been validated in the Polish population (5).

After completion of development of teeth, estimation of age of a living adult becomes even more challenging as many methods are destructive and cannot be applied in vivo. The aging of a tooth, as an age estimating method, is promising (6). Examples of these age-related changes, which had been proved reliable, include periodontal status, attrition, apical root resorption, cementum deposition, root 
smoothness and secondary dentin deposition (7). Based on this features, several methods were established. Aspartic acid racemization is a method that was elaborated to evaluate biochemical changes in teeth. It relies on continuous age-related increase in the amount of D-aspartic acid in dentin. The ratio of $\mathrm{D}$-aspartic acid to $\mathrm{L}$-aspartic acid is calculated, called the ratio of racemization, and used for dental age estimations. However, aspartic acid racemization is both a time-consuming and expensive method $(8,9)$. Another drawback to this method, already studied in a Polish population sample, is that it requires the use of extracted teeth, which can be an ambiguous starting point for evaluating the age of a living person (10).

Thus researchers searched for ways of applying radiographs of teeth to estimate dental age and subsequently the age of an individual. Kvaal et al. (11) were the first to employ such an approach by measuring secondary dentine deposition on radiographs, calculating the length and width of the pulp and tooth. The method performs properly, however requires a number of teeth to be measured and takes multiple measurements and calculations in order to evaluate the age of a living. In 1997, Drusini et al. $(7,12)$ described a method to similar to the one by Kvaal, proving the appropriateness of age estimating by tooth aging. In more recent studies Cameriere et al. (13) described a new way of calculating the pulp to tooth area ratio (AR) in canines in radiographs. It is the canines which are used for dental age estimations, because they seem to be the most reliable teeth to measure the age of an individual. They are single rooted and possess the largest pulp areas when compared to other anterior teeth (12). Furthermore, canines survive longer than any other teeth regardless of age, being the most resistant to wearing (14). This dental aging method does not take much time and needs only one tooth to be measured, allowing to evaluate the age of a patient even if only one tooth is present. With brisk development of image processing in digital radiography, dental age assessment has become significantly more accessible (15).

The aim of this paper is to validate the method of estimating age by evaluation of the secondary dentine apposition using pulp/tooth area ratio in upper canines in a sample of Polish population.

\section{Materials}

Optimum diagnostic quality orthopantomographs (OPGs) were retrieved from the digital database of the Department of Dentomaxillofacial Radiology of the Medical University of Lublin, Poland. The analyses were carried out on subsequent 521 OPGs meeting the inclusion criteria, taken in patients in the years 2015-2018, including 271 females and 250 males. The study group consisted of Polish individuals aged from 18 to 70 years (mean age of 38.22 years, median age 36.0), divided into 6 age subgroups (Table 1). Age distribution of males and females did not differ significantly ( $p=0.54, \mathrm{U}$ Mann-Whitney test).

Table 1. Age distribution of the study sample.

All radiographs were taken by means of the VistaVox (Dürr Dental, Minto, Germany) digital panoramic machine. The device provides the benefit of shorter exposure time than in many other similar machines, which reduces potential motion artefacts. Moreover, image quality is enhanced due to application of the 
so-called S-Pan technology, which relies on automatic choice of the most sharp areas within up to 20 registered parallel, thin slice X-ray images performed during image software processing. All OPGs used in this study were taken due to different clinical indications (such as impacted teeth, dental anomalies, orthodontic or implant follow-up), and not for the purpose of the research.

The selection criteria included: presence of an upper right canine free from any pathology i.e. with no caries, attrition, abrasion, impaction, fracture, neither treated endodontically, nor having any dental fillings.

First, chronological age of each subject was calculated by subtracting the date of birth from the date of taking the OPG.

Subsequently, all OPGs were saved as high-resolution JPEG files on a PC and post-processed using the Corel Photo Paint X7 software (Corel, Ottawa, Ontario, Canada). A magnetic lasso-tool provided in this software was used to trace the margins of the upper right canines as well as their pulp outlines (Fig. 1, 2). Once the contours are traced, the software highlights the area of a tooth and its pulp, and the area is given in pixels. Then the ratio of tooth to pulp area (AR) was calculated for each maxillary right canine.

In order to estimate the dental age, the following formulas were used:

The age estimation DA has been obtained by using the original Cameriere's formula for upper canines (15):

$D A=101.3-556.68$ AR

A regression equation to predict the chronological age when only upper canine is used modified for the Indian population (12):

$D A=96.795-513.561$ AR

The reason why a formula for Indian population was chosen was to verify whether a promising formula in other population may perform better than the original Cameriere's formula.

All measurements were performed by one observer (NN). One month later every $5^{\text {th }}$ OPG was reexamined by the first observer (NN) as well as by the second observer (MP), to test the inter- and intraobserver reliability. Both observers were blinded to patient's chronological age and gender in order to avoid bias. Then interclass correlation coefficient was calculated.

Statistical analysis was performed using the Statistica for Windows software (StatSoft, Tulsa, OK, USA) as well as Statistical Package for the Social Sciences (SPSS software, IBM Corporation, New York, NYC, USA).

Pearson's correlation coefficient was applied to verify presence and strength of correlation between chronological age and age estimated using the AR. 
Estimates of age were compared for the original formula by Cameriere (15) and its modification for the Indian population proposed by Jeevan (12).

Regression models were developed for prediction of the chronological age using the AR in the Polish sample.

The consent from the local bioethical committee was obtained (no. KE-0254/341/2018).

\section{Results}

The intra- and interobserver intra-class correlations equaled $0.87(95 \% \mathrm{Cl} 0.815-0.91)$ and $0.867(95 \% \mathrm{Cl}$ 0.81-0.908) respectively.

The Shapiro-Wilk test proved that the distribution of data was not Gaussian $(\mathrm{p}<0.05)$.

Descriptive statistics of the real and estimated ages is presented in the Table 2.

Table. 2. Descriptive statistics of the real age and estimated ages.

Table 3. Pearson's correlation coefficients for relationships between the morphologic variables and age in males, females and the total group.

Pearson's correlation coefficients between chronological age and age estimated basing on AR presented a significant inverse correlation. The correlation coefficient equaled -0.844 , which means that the relationship is very strong for the total group. In males it was -0.815 , while in females -0.873 . All these correlations were strong and statistically significant (Table 3 ).

*statistically significant correlationsAR - pulp/tooth area ratio

The regression models for the Polish population were as follows:

In the total group:

$\mathrm{DA}=91.746-481.6 \mathrm{AR}$

In females:

$\mathrm{DA}=91.735-486,4 \mathrm{AR}$

In males:

$\mathrm{DA}=91.802-476,7 \mathrm{AR}$

Table 4 presents the results of estimation of dental age according to Cameriere, Jeevan and the Polish formula versus the real age. 
The median of the absolute values between real age and estimated dental age was 3.9 years with quartile range 5.60 years, when the own modification of the formula was used. In comparison, according to the original formula by Cameriere, the median of the absolute values was higher and equaled 4.2 years with quartile range 6.1 years.

Moreover there were no statistically significant differences between the real age and estimated age using the Polish formula $(p=0.34)$, while application of the formulas by Cameriere and Jeevan resulted in statistically significant difference $(p=0.00)$. At the same time no differences between the two tested nonPolish formulas for estimation of age basing on upper canines pulp/tooth area ratio were observed, and the correlation was full $(r=1)$.

No differences in AR according to gender were proved $(p=0.858)$.

\section{Discussion}

The issue of age estimation in living adults is getting more important along with increased numbers of illegal immigrants entering e.g. European Union without valid identity documents and/or verifiable birth certificate $(1,11,13)$. Since taking radiographs solely for forensic purposes is ethically questionable due to potential burden of ionizing radiation, methods basing on existing X-ray images are highly desired. OPGs provide images of both anterior and posterior teeth registered during a single, relatively short, X-ray exposure what makes it an ideal tool for dental evaluation. No further radiographic examinations need to be performed (7).

Indeed, age estimation by pulp/tooth ratio can be done also on the basis of intraoral periapical radiographs (16). For this purpose taking mesial and vestibular periapical X-rays was proposed, but this approach is not feasible in living adults as technically it is impossible to take radiographs in mesial projections of teeth present in dental arches (17). Well-established techniques of taking periapical X-rays in labio-vestibular projections like paralleling technique and bisected angle technique are prone to technical errors, especially the latter one. Moreover these radiographs are not always easy to obtain in clinical settings e.g. in case of gagging reflex, only canine present in dental arch which may result in unstable position of image sensor during exposure, in patients with lockjaw etc. Therefore OPGs remain an alternative to intraoral periapical radiographs, especially when they are taken due to clinical indications, and not for the purpose of forensic investigations.

Recently Cone-Beam Computed Tomography ( $\mathrm{CBCT}$ ), cross-sectional imaging technique applied among others in dentomaxillofacial radiology, has been tested for dental age estimation using the pulp/tooth ratio. The study based on Korean adults involved the largest buccolingual and horizontal dimensions of canines, while in Malaysian population volumetric changes in pulp cavity occurring with age were registered $(18,19)$. On the other hand, in a group of 91 subjects examined by CBCT in the material of De Angelis et al. (14) the rate of pulp chamber volume and total volume of an upper canine was estimated. CBCT seems promising in forensic applications as it is characterized by a much lower image distortion than OPGs. However, potential drawbacks of CBCT in dental age estimation in comparison with two- 
dimensional radiographs (intraoral periapical and OPG), are lower image resolution, still lower availability of equipment as well as usually higher X-ray dose than in case of OPGs and definitely higher than that of periapical radiographs (20). One more advantage of OPG over periapical radiographs is demonstration of all 4 permanent canines in one radiograph, instead of taking 4 separate periapical views which yields four exposures to ionizing radiation. However, this was not the case in the current study due to reasons mentioned below as limitations.

Both digitized and digital (direct or indirect) radiographs as well as different methods of AR tracing were proposed in research studies $(16,21)$. For example, Saxena (21) measured lengths of tooth, pulp and root at 3 levels - cemento-enamel junction, middle of the root and halfway between these two points. In the present study lasso tool of the commercially available image processing software was used to manually trace the outlines of each tooth and its pulp.

Estimation of dental age by means of the AR is not restricted only to canines, nonetheless these teeth appear to be the foremost suitable for the method. Not only their anatomy is simple, but they also are preserved in the oral cavity longer than other teeth groups $(12,14)$. Moreover, maxillary canines have been shown to be more predictive than lower canines (standard error of estimate 2.37 years vs. 2.55 years) (22). Hence we decided to base on the image of upper maxillary canine only for the purpose of this study.

Ex vivo research demonstrating validity of $A R$ method included age at death estimation in a sample of 20th -century Mexican prisoners as well as individual age estimation in adult Neolithic skeletons in Italy, Middle-Ages skeletons in Italy, collections of skulls from Bologna, Italy, and canines from Coimbra, Portugal (22-26). In all these studies AR provided estimates which were significant in terms of forensic dentistry and archeology, respectively. The research on Portuguese sample yielded a much lower error of age estimation, i.e. 2.5 years, than the one derived from anthropological methods reaching 5 years (22).

The samples from the following populations have already been tested for application of the pulp/tooth area ration in dental age estimation of living subjects: Italian (23), Indian (12,21), Brazilian (27) and Iranian (28).

In the material of 100 digitized OPGs of Italian white Caucasians the pulp/tooth area ratio of right upper canine was highly correlated with calendar age of studied individuals (23). Standard error of estimate reached 5.35 years, while the absolute value of residual error was lower than 4 years.

The next population sample to be found in literature was the Indian one (21). In 120 OPGs of patients of both genders aged from 21 to 60 years, there were no statistically significant differences between chronological and estimated dental ages, both in males and females. Another Indian sample was evaluated basing on digital periapical radiographs and consisted of 228 subjects aged from 16 to 62 years (12). It confirmed that gender did not influence the AR of canines in a significant way, and this observation proved true also for the studied Polish population sample. 
Brazilian sample used for dental age estimation using pulp/tooth ratio consisted of individuals aged from 20 to 87 years, assigned to 5 groups consisting of 80 subjects, apart from the oldest age group over 70 years of age, in which there were not enough X-rays of individuals meeting the inclusion criteria. In this population the mean error of estimate was higher as in previously quoted studies and reached from 7.96 to 9.68 years. It is worth underlining that the largest errors affected extreme age groups, i.e. 20-29 years and over 60 years. Once a formula for DA estimation dedicated to the studied population was elaborated, the mean error decreased to $7.99-8.56$ years (27). Following this observation, we decided to propose separate formulas for the Polish sample, which proved useful.

Three hundred OPGs were submitted for DA estimations using pulp/tooth area ratio in an Iranian study by Dehghani et al. (28). A total of 542 upper and lower canines of patients aged from 16 to 64 were included in the analysis following rejection of OPGs not meeting the selection criteria. The quoted results confirmed usefulness of AR in estimation of chronological age of living adult individuals.

To the best Authors' knowledge, this is the first study validating the pulp/tooth area ratio in the Polish population. It seems that age estimation by means of AR is a relatively simple, rapid, convenient and inexpensive method for forensic purposes. Preliminary results of this study prove that even if only one canine is present, dental age estimation can still be performed.

Limitations of the study include restriction of the evaluation only to the maxillary right canine. This is due to high caries prevalence in the Polish population and edentulism rate in older age groups. An average number of teeth for a person living in a big Polish city over the age of 65 is only 14.3, however people from small cities have two teeth less according to the survey from 2013 (29). The situation in a younger group of patients appears to be better since the average count of teeth in the age group 35-44 years is between 24.5 and 25 teeth. It also influenced the number of OPGs included in the study as all consecutive radiographs fulfilling selection criteria taken during 4 years in our Department were gathered in the study, and it yielded 521 radiographs out of 3316 that had been done.

Another limitation might be the use of panoramic radiography instead of periapical X-rays, but in our opinion the most up-to-date direct digital panoramic machines, like the one used in our study, provide very clear images when compared to digitalized analogue OPGs obtained by means of earlier generations of equipment. Potential image distortion as an inherent feature of OPG is greatly reduced by application of area ratio in contrast to linear measurements which are prone to error.

\section{Conclusions}

Pulp to tooth area ratio can be used as dental age estimate in the Polish population. Single upper canine assessment is sufficient to assess dental age, which is useful in populations characterized by high caries prevalence and edentulism rate.

\section{Declarations}


- Ethics approval and consent to participate:

Medical University of Lublin committee's reference number KE-0254/341/2018.

- Consent for publication

Not applicable

- Availability of data and materials

Data sharing is not applicable to this article as no datasets were generated or analysed during the current study

- Competing interests :

The authors declare that they have no competing interests

- Funding

Source of financial support: University internal funding DS242/2019

- Authors' contributions

IRK: Conceptualization, Methodology, Writing - Review \& Editing; PK: Formal analysis, Visualization; MP: Validation; NN: Methodology , Investigation, Writing - Original Draft, Funding acquisition

- Acknowledgements

Not applicable

- Authors' information (optional)

\section{References}

1. Cameriere R, Ferrante L. Canine pulp ratios in estimating pensionable age in subjects with questionable documents of identification. Forensic Sci Int [Internet]. 2011;206(1-3):132-5. Available from: http://dx.doi.org/10.1016/j.forsciint.2010.07.025

2. Rózyło-Kalinowska I, Kiworkowa-Raczkowska E, Kalinowski P. Dental age in Central Poland. Forensic Sci Int. 2008 Jan 30;174(2-3):207-16.

3. Prasad M, Ganji VSK, George SA, Talapaneni AK, Shetty SK. A comparison between cervical vertebrae and modified MP3 stages for the assessment of skeletal maturity. J Nat Sci Biol Med. 2013;4(1):7480.

4. Róyło-Kalinowska I, Kolasa-Rczka A, Kalinowski P. Relationship between dental age according to Demirjian and cervical vertebrae maturity in Polish children. Eur J Orthod. 2011 Feb;33(1):75-83. 
5. Różyło-Kalinowska I, Kalinowski P, Kozek M, Galić I, Cameriere R. Validity of the third molar maturity index I3M for indicating the adult age in the Polish population. Forensic Sci Int. 2018;

6. Oliveira RN, Silva SFSM, Kawano A, Antunes JLF. Estimating age by tooth wear of prehistoric human remains in Brazilian archaeological sites. Int J Osteoarchaeol. 2006;16(5):407-14.

7. Hatice BD, Nihal A, Nursel A, Humeyra Ozge Y, Goksuluk D. Applicability of Cameriere's and Drusini's age estimation methods to a sample of Turkish adults. Dentomaxillofac Radiol. 2017;

8. Ohtani S, Yamada Y, Yamamoto I, Marumo T, Sugeno H, Sugimoto H, et al. Estimation of age from teeth using the racemization of aspartic acid (racemization method). Japanese Journal of Legal Medicine. 2000.

9. Gulsahi A, Kulah CK, Bakirarar B, Gulen O, Kamburoglu K. Age estimation based on pulp/tooth volume ratio measured on cone-beam CT images. Dentomaxillofacial Radiol. 2018;47(1):11-6.

10. Wochna K, Bonikowski R, Śmigielski J, Berent J. Aspartic acid racemization of root dentin used for dental age estimation in a Polish population sample. Forensic Sci Med Pathol. 2018;

11. Cattaneo C, De Angelis D, Ruspa M, Gibelli D, Cameriere R, Gandi M. How old am I? Age estimation in living adults: A case report. J Forensic Odontostomatol. 2008;26(2):39-43.

12. Jeevan MB, Kale AD, Angadi P V., Hallikerimath $S$. Age estimation by pulp/tooth area ratio in canines: Cameriere's method assessed in an Indian sample using radiovisiography. Forensic Sci Int. 2011;204(1-3):209.e1-209.e5.

13. Cameriere R, Ferrante L, Cingolani M. Variations in Pulp/Tooth Area Ratio as an Indicator of Age: a Preliminary Study. J Forensic Sci. 2004;49(2):1-3.

14. De Angelis D, Gaudio D, Guercini N, Cipriani F, Gibelli D, Caputi S, et al. Age estimation from canine volumes. Radiol Medica [Internet]. 2015;120(8):731-6. Available from:

http://dx.doi.org/10.1007/s11547-015-0521-5

15. Cameriere R, De Luca S, Egidi N, Bacaloni M, Maponi P, Ferrante L, et al. Automatic age estimation in adults by analysis of canine pulp/tooth ratio: Preliminary results. J Forensic Radiol Imaging [Internet]. 2015;3(1):61-6. Available from: http://dx.doi.org/10.1016/j.jofri.2014.10.001

16. Azevedo AC, Michel-Crosato E, Biazevic MGH, Galić I, Merelli V, De Luca S, et al. Accuracy and reliability of pulp/tooth area ratio in upper canines by peri-apical X-rays. Leg Med. 2014;

17. Cameriere R, Ferrante L, Belcastro MG, Bonfiglioli B, Rastelli E, Cingolani M. Age estimation by pulp/tooth ratio in canines by peri-apical X-rays. J Forensic Sci. 2007;52(1):166-70.

18. Asif MK, Nambiar P, Mani SA, Ibrahim NB, Khan IM, Lokman NB. Dental age estimation in Malaysian adults based on volumetric analysis of pulp/tooth ratio using CBCT data. Leg Med [Internet]. 2019;36(October 2018):50-8. Available from: https://doi.org/10.1016/j.legalmed.2018.10.005

19. Lee SM, Oh S, Kim J, Kim YM, Choi YK, Kwak HH, et al. Age estimation using the maxillary canine pulp/tooth ratio in Korean adults: A CBCT buccolingual and horizontal section image analysis. $J$ Forensic Radiol Imaging [Internet]. 2017;9(November 2016):1-5. Available from: http://dx.doi.org/10.1016/j.jofri.2016.12.001 
20. Ludlow JB, Timothy R, Walker C, Hunter R, Benavides E, Samuelson DB, et al. Ffective dose of dental CBCT - A meta analysis of published data and additional data for nine CBCT units. Dentomaxillofacial Radiology. 2015.

21. Saxena S. Age estimation of Indian adults from orthopantomographs. Braz Oral Res. 2011;

22. Cameriere R, Cunha E, Sassaroli E, Nuzzolese E, Ferrante L. Age estimation by pulp/tooth area ratio in canines: Study of a Portuguese sample to test Cameriere's method. Forensic Sci Int. 2009;193(13):128.e1-128.e6.

23. Cameriere R, Ferrante L, Belcastro MG, Bonfiglioli B, Rastelli E, Cingolani M. Age estimation by pulp/tooth ratio in canines by peri-apical X-rays. J Forensic Sci. 2007;52(1):166-70.

24. Cameriere R, Brogi G, Ferrante L, Mirtella D, Vultaggio C, Cingolani M, et al. Reliability in age determination by pulp/tooth ratio in upper canines in skeletal remains. J Forensic Sci. 2006;51(4):861-4.

25. Fabbri PF, Viva S, Ferrante L, Lonoce N, Tiberi I, Cameriere R. Radiological tooth/pulp ratio in canines and individual age estimation in a sample of adult neolithic skeletons from Italy. Am J Phys Anthropol. 2015;158(3):423-30.

26. De Luca S, Bautista J, Alemán I, Cameriere R. Age-at-Death Estimation by Pulp/Tooth Area Ratio in Canines: Study of a 20th-Century Mexican Sample of Prisoners to Test Cameriere's Method. J Forensic Sci. 2011;56(5):1302-9.

27. Azevedo A de CS, Alves NZ anin., Michel-Crosato E, Rocha M, Cameriere R, Biazevic MG abriel. H. Dental age estimation in a Brazilian adult population using Cameriere's method. Braz Oral Res. 2015;29(1):1-9.

28. Dehghani M, Shadkam E, Ahrari F, Dehghani M. Age estimation by canines' pulp/tooth ratio in an Iranian population using digital panoramic radiography. Forensic Sci Int [Internet]. 2018;285:44-9. Available from: https://doi.org/10.1016/j.forsciint.2018.01.016

29. The state of oral health and its determinants in the Polish population aged 35-44 and 65-74 in 2013 [Internet]. 2013 [cited 2019 Oct 20]. Available from: https://www.gov.pl/web/zdrowie/monitorowaniestanu-zdrowia-jamy-ustnej-populacji-polskiej-w-latach-2016-2020

\section{Tables}

Table 1. Age distribution of the study sample.

\begin{tabular}{c|ccc} 
GROUP & AGE & COUNT & $\%$ OF ALL CASES \\
\hline GROUP I & $18-20$ & 20 & 3.83 \\
GROUP II & $21-30$ & 173 & 33.20 \\
GROUP III & $31-40$ & 111 & 21.30 \\
GROUP IV & $41-50$ & 112 & 21.49 \\
GROUP V & $51-60$ & 68 & 13.05 \\
GROUP VI & $61-70$ & 37 & 7.10
\end{tabular}


Table. 2. Descriptive statistics of the real age and estimated ages.

\begin{tabular}{|l|c|c|c|r|r|c|}
\hline Variables & Valid $\mathrm{n}$ & Mean & Median & Minimum & Maximum & Std.Dev. \\
\hline Age & 521 & 38.22457 & 36.00000 & 18.0000 & 70.00000 & 13.24189 \\
\hline Dental Age-Cameriere & 521 & 39.71644 & 38.10174 & 14.4249 & 70.73718 & 11.91806 \\
\hline Dental Age-Jeevan & 521 & 39.42908 & 37.67880 & 12.0140 & 73.05435 & 12.91871 \\
\hline Dental Age Polish & 521 & 38.21968 & 36.70546 & 14.5021 & 67.30987 & 11.17635 \\
\hline
\end{tabular}

Table 3. Pearson's correlation coefficients for relationships between the morphologic variables and age in males, females and the total group.

\begin{tabular}{|l|c|c|c|c|c|c|}
\hline & \multicolumn{2}{|c|}{ Males } & \multicolumn{2}{c|}{ Females } & \multicolumn{2}{c|}{ Total } \\
\hline & $\mathrm{r}$ & $\mathrm{p}$ & $\mathrm{r}$ & $\mathrm{p}$ & $\mathrm{r}$ & $\mathrm{p}$ \\
\hline Pulp chamber & 0.638 & $0.000^{\star}$ & -0.682 & $0.000^{\star}$ & -0.62 & $0.000^{\star}$ \\
\hline Tooth area & 0.000 & $0.000^{\star}$ & -0.101 & 0.096 & -0.03 & 0.530 \\
\hline AR & -0.815 & $0.000^{\star}$ & -0.873 & $0.000^{\star}$ & -0.844 & $0.000^{\star}$ \\
\hline Age acc. to formula by Cameriere & 0.815 & $0.000^{\star}$ & 0.873 & $0.000^{*}$ & 0.844 & $0.000^{\star}$ \\
\hline Age acc. to formula by Jeevan & 0.815 & $0.000^{\star}$ & 0.873 & $0.000^{\star}$ & 0.844 & $0.000^{\star}$ \\
\hline Age acc. to the Polish formula & 0.815 & $0.000^{\star}$ & 0.873 & $0.000^{*}$ & 0.844 & $0.000^{\star}$ \\
\hline
\end{tabular}

AR - pulp/tooth area ratio

*statistically significant correlations

\section{Figures}




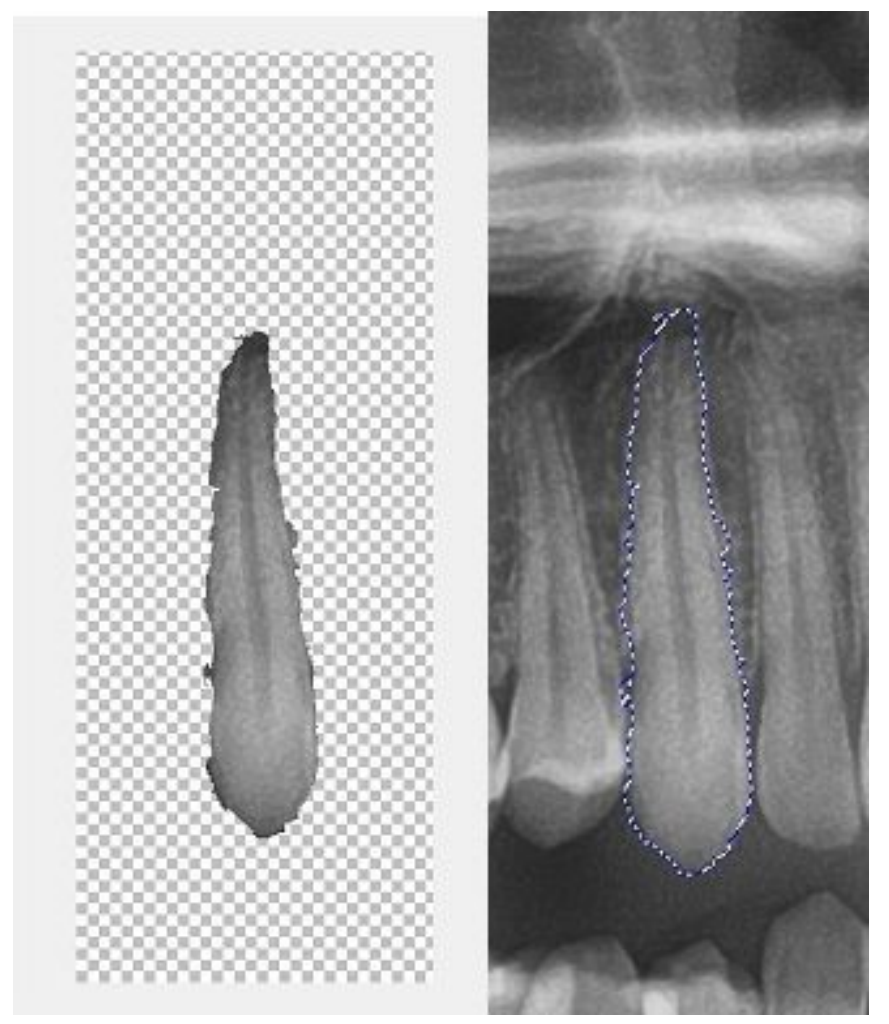

\section{Figure 1}

Lasso-tool software enabling to outline the upper right canine in a cropped OPG.
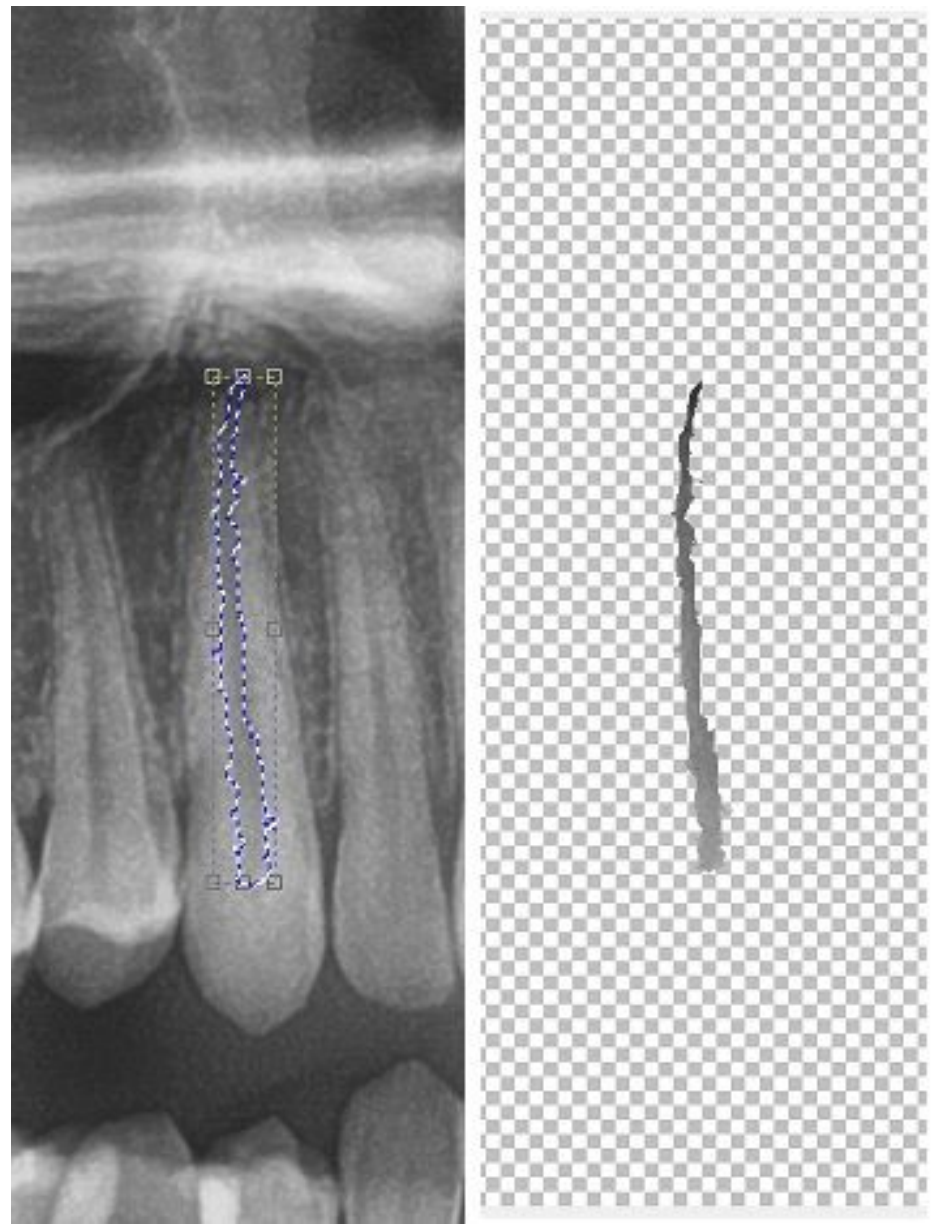
Figure 2

An example of extracted canine's pulp using lasso-tool in a cropped OPG.

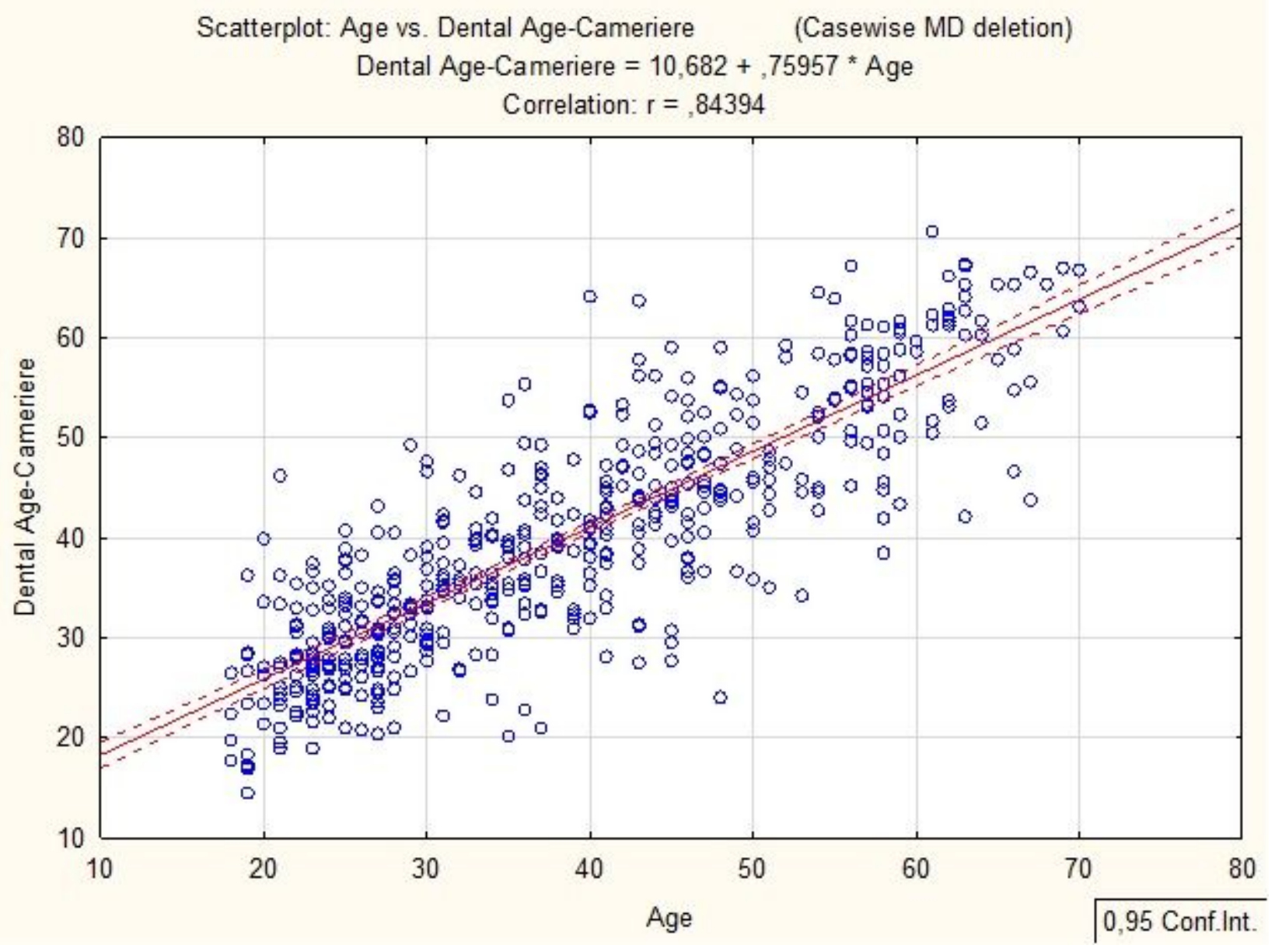

Figure 3

Correlation between chronological age and dental age calculated with the use of Cameriere's formula for upper canines in Polish population. 


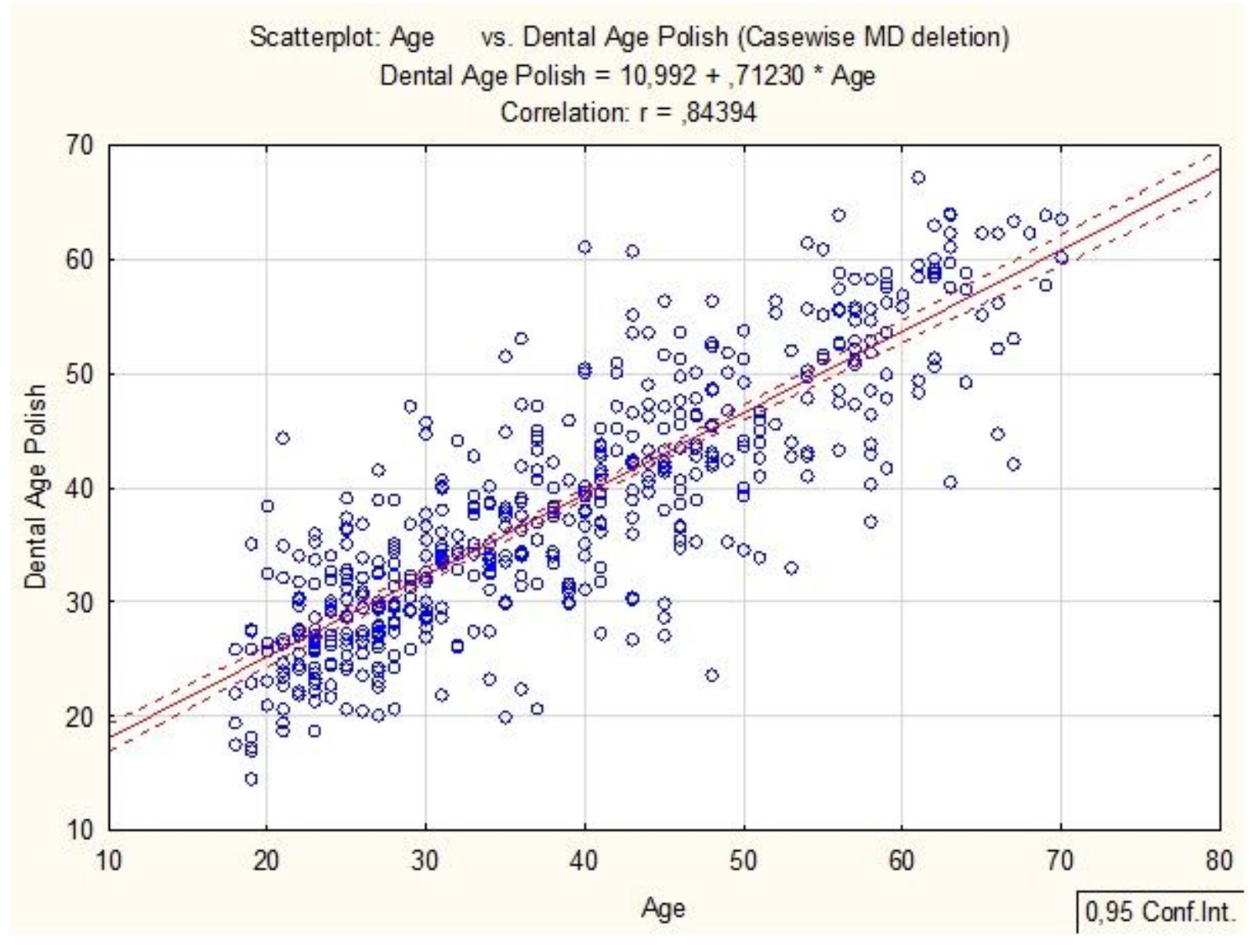

Figure 4

Correlation between chronological age and dental age estimated using the Polish modification of the formula for upper canines in Polish population. 